\title{
Symmetry characterization in molecular multiphoton spectroscopy
}

\author{
David L. Andrews \\ School of Chemical Sciences, University of East Anglia, Norwich NR4 7TJ, U.K.
}

(Received 26 March 1989; in final form 3 July 1989; accepted 7 July 1989)

\begin{abstract}
In this paper it is shown how simple application of irreducible tensor calculus provides a powerful method for the symmetry characterization of a wide range of multiphoton transitions in solids, liquids or gases. These methods provide for a systematic classification of distinct symmetry classes for any multiphoton process and facilitate devising suitable polarization studies for spectroscopic application. General results for multiphoton processes up to and including those involving four-photon interactions are presented in the tables for all the common molecular and crystallographic point groups. A new symmetry class labelling scheme is also introduced. Applications are illustrated by reference to two-, three- and four-photon absorption, resonance and non-resonance Raman scattering and hyper-Raman scattering. Whilst the examples principally involve electric dipole coupling, it is demonstrated how the effects of higher multipoles may he incorporated into the results.
\end{abstract}

\section{INTRODUCTION}

MUCH OF the theory of multiphoton spectroscopy is strongly influenced by its historical development. The conceptually simplest multiphoton process, two-photon absorption, was first predicted by GÖPPERT-MAYER in 1931 in a paper which also provided a basis for the description of the recently discovered Raman scattering effect [1]. The strong similarity between these two-photon processes naturally leads to a similarity in their quantum mechanical selection rules, and so when the first experimental observations of two-photon absorption were made by KAISER and GARRETT some 30 years later [2], a theoretical framework for dealing with its symmetry properties was already long established. This framework is exemplified by the common inclusion in molecular point group character tables of the transformation properties of translation and rotation vectors and quadratic translation terms.

However valuable such tables are, they are not optimally suited to an extension to higher order multiphoton processes, as some of the confusions which have arisen over the hyper-Raman effect lucidly illustrate. Indeed, if Raman theory were to be developed afresh today, the insights which have now been gained from a broader understanding of nonlinear laser spectroscopy would undoubtedly result in a somewhat different approach to the description of symmetry characteristics. It is the purpose of this paper to show how simple application of irreducible tensor methods provides the most convenient and direct pathway to the symmetry characterization of multiphoton transitions, and one which is much less beset with pitfalls.

\section{IrReducible Tensor Formulation}

Any tensor may be expressed as a sum of irreducible tensors which transform under irreducible representations of the full rotation group. Irreducible tensors facilitate the analysis of spectroscopic selection rules and are traditionally treated as spherical tensors in the formalism of angular momentum theory. The theoretical description of multiphoton processes nonetheless frequently involves vector and tensor properties which are most conveniently expressed in Cartesian form; moreover, Cartesian tensors have the advantage of clearly exhibiting directional behaviour which is often obscured in spherical tensors. As a result, the derivation of explicit formulae for the irreducible components of Cartesian tensors has received extensive treatment in recent years and full results up to rank four are now available in the literature [3-5]. For the purposes of symmetry characterization discussed below, however, the explicit results are not required. 
In the generally valid electric dipole approximation, the rate of an $n$-photon transition may be expressed by the relation:

$$
\Gamma=K_{n}\left|S_{n} \odot^{n} T_{n}\right| 2,
$$

where $S_{n}$ is a rank $n$ radiation tensor comprising a product of polarization vectors for each of the photons involved in the process, $T_{n}$ is a rank $n$ molecular response tensor and the symbol $\odot^{n}$ signifies an $n$-fold tensor contraction (a non-linear counterpart to the scalar product of two vectors). Polarization vectors are treated as complex quantities to admit the possibility of circular polarizations and they are conjugated for emitted photons. For example, in the case of Raman scattering where $n=2, T_{2}$ is the second rank Raman tensor, and $S_{2}$ can be identified with $e \bar{e}^{\prime}$ where $e$ is the polarization vector for the absorbed photon and $\bar{e}^{\prime}$ is the complex conjugate of the polarization vector for the scattered photon.

All multiphoton selection rules ultimately result from the requirement that for any given transition to take place, $S_{n} \odot^{n} T_{n}$ must be non-zero. In deciding whether a given transition is allowed or forbidden, there are two aspects to consider; the first concerns the implications of molecular symmetry for the tensor $T_{n}$ and the second the consequences for the tensor $S_{n}$ of the radiation field properties. Even if each of these tensors has non-zero components, however, their tensor contraction may still vanish just as the scalar product of two finite but orthogonal vectors vanishes. It is at this stage that the introduction of irreducible tensor calculus permits a more detailed analysis of the problem and one which is equally applicable to solids, liquids or gases.

Each irreducible tensor $T_{n}^{(j)}$ of rank $n$ is characterized by a weight $j \leqslant n$ and possesses $(2 j+1)$ independent components. The reduction of a Cartesian tensor $T_{n}$ generally results in a sum of such irreducible tensors, with some weights represented more than once and therefore distinguished by a secondary label $q$. Starting with the general case of a tensor without explicit index symmetry properties, we can therefore write:

$$
T_{n}=\sum_{j=0}^{n} T_{n}^{(j)},
$$

where

$$
T_{n}^{(j)}=\sum_{q=1}^{N_{n}^{(j)}} T_{n}^{(j ; q)},
$$

and $N_{n}^{(i)}$ is the multiplicity of weight $j$ in the reduction scheme.

Using Eqn (2) together with its counterpart for the reduction of the tensor $S_{n}$, the multiphoton transition rate given by Eqn (1) can be written as:

$$
\Gamma=K_{n}\left|\sum_{j^{\prime}=0}^{n} S_{n}^{\left(j^{\prime}\right)}, \bigodot^{n} \sum_{j=0}^{n} T_{n}^{(j)}\right|^{2}
$$

However the general index symmetry properties of irreducible tensors are such that the cross-terms of Eqn (4) where $j^{\prime} \neq j$ identically vanish. Thus the rate may be more simply expressed as:

$$
\Gamma=K_{n}\left|\sum_{j=0}^{n} S_{n}^{(j)} \odot^{n} T_{n}^{(j)}\right|^{2} .
$$

Equation (5) is the key to understanding the symmetry analysis developed below. If any term $S_{n}^{(j)} \bigodot^{n} T_{n}^{(j)}$ in the summation over $j$ is non-zero, then in the absence of accidental cancellations between different weights, the transition rate will be finite and the transition therefore allowed. This means that there must be at least one weight, i.e. one value of $j$, for which both $S_{n}^{(j)}$ and $T_{n}^{(j)}$ are non-zero. 


\section{INDEX SYMmETRY CONSIDERATIONS}

The multiplicity with which each tensor weight is represented in the reduction of a general reducible tensor can be derived using a recursive scheme due to GEL'FAND et al. [6]; the general result is given by the following formula [7]:

$$
N_{n}^{(j)}=\sum_{k}(-1)^{k} \frac{(2 n-3 k-j-2) ! n(n-1)}{(n-3 k-j) !(n-k) ! k !},
$$

where $0 \leqslant k \leqslant\left[\frac{1}{3}(n-j)\right]$. Since each irreducible tensor has $(2 j+1)$ independent components, the total number of components in the reduction is:

$$
\sum_{j=0}^{n}(2 j+1) N_{n}^{(j)}=3^{n}
$$

as required.

The multiplicities of each weight for tensors up to rank four are shown in Table 1. When a tensor possesses index symmetry, as indicated by brackets around its subscript rank, the multiplicity of most weights is diminished, as this table shows. For example a third rank tensor with symmetry in two of its three indices, denoted by $T_{1(2)}$, has no $j=0$ contributions and a third rank tensor with full index symmetry, denoted by $T_{(3)}$, has no contributions from either $j=0$ or $j=2$. In fact, only alternate weights from $n$ downwards are represented in rank $n$ tensors with full index symmetry, and here the multiplicity of each weight is 1 . The representations of tensors with partial index symmetry are obtained by coupling the appropriate non-symmetric and fully-symmetric tensors of lower rank. For example the tensor $T_{1(2)}$ has an irreducible representation obtained by coupling the results for the vector $T_{1}$ (three components, weight 1 ) with the index-symmetric second rank tensor $T_{(2)}$ (six components, weights 0 and 2). In view of such implications, it becomes important to assess the factors involved in determining index symmetry in $S_{n}$ and $T_{n}$.

\subsection{Index symmetry in the radiation tensor}

Any index symmetry in the radiation tensor must result from two or more photon polarization vectors being equivalent (subject to complex conjugates being taken for emitted photons, as noted earlier). Thus, for example, in a polarized Raman spectrum

Table 1. Number of independent components $X$ and multiplicity of each weight $j$ in the irreducible representation of Cartesian tensors

\begin{tabular}{lcccccc}
\hline & $X$ & $j=0$ & $j=1$ & $j=2$ & $j=3$ & $j=4$ \\
\hline Rank 1 & & & & & & \\
$T_{1}$ & 3 & 0 & 1 & & & \\
Rank 2 & & & & & & \\
$T_{2}$ & 9 & 1 & 1 & 1 & & \\
$T_{(2)}$ & 6 & 1 & 0 & 1 & & \\
Rank 3 & & & & & & \\
$T_{3}$ & 27 & 1 & 3 & 2 & 1 & \\
$T_{1(2)}$ & 18 & 0 & 2 & 1 & 1 & \\
$T_{(3)}$ & 10 & 0 & 1 & 0 & 1 & \\
Rank 4 & & & & & & \\
$T_{4}$ & 81 & 3 & 6 & 6 & 3 & 1 \\
$T_{2(2)}$ & 54 & 2 & 3 & 4 & 2 & 1 \\
$T_{(2)(2)}$ & 36 & 2 & 1 & 3 & 1 & 1 \\
$T_{1(3)}$ & 30 & 1 & 1 & 2 & 1 & 1 \\
$T_{[(2)(2) !}$ & 21 & 2 & 0 & 2 & 0 & 1 \\
$T_{(4)}$ & 15 & 1 & 0 & 1 & 0 & 1 \\
\hline
\end{tabular}


where only photons with linear polarization parallel to that of the incident light are collected, the second rank radiation tensor is index-symmetric and can be written as $S_{(2)}$. Here, as shown by Table 1 , only weights 0 and 2 are represented. In the corresponding depolarized Raman spectrum, however, the linear polarization vectors of the absorbed and scattered photons differ as they are perpendicular; hence there is no index symmetry and the radiation tensor $S_{2}$ has contributions from each weight $j=0,1$ and 2 . Other special features arise in connection with circular polarizations, as will be shown in a later section.

\subsection{Index symmetry in the molecular tensor}

Index symmetry in the molecular tensor results from an equivalence in frequency between two or more of the photons involved in the process. Thus, for any multiphoton absorption study based on a single laser beam, all photons have the same frequency and full index symmetry ensues. For example, as Table 1 shows, single-beam three-photon absorption studies are associated with a molecular response tensor of the form $T_{(3)}$ which has contributions of weights 1 and 3 alone. Approximate index symmetry of a different kind arises in the case of non-resonance Raman scattering, where the appropriate tensor $T_{(2)}$ carries only weights 0 and 2 ; however, at the onset of resonance the approximation breaks down and the molecular response must be characterized by a non-symmetric tensor $T_{2}$ with all weights $j=0,1$ and 2 present.

\section{Irreducible Tensor Representations}

For any allowed multiphoton transition, it is necessary that the molecular response tensor must possess at least some non-zero elements. The criterion for this rule to be satisfied is that the product of the irreducible representations of the initial and the final states of the molecule must be spanned by one or more components of the tensor [8]. In the common case of transitions originating from, or terminating in, a totally symmetric ground state, this reduces to a requirement that one of the irreducible parts of the tensor transforms under the same representation as the excited state. Since the rule is easiest to apply in this case, it is this situation which is assumed in the following, although the extension to other cases is perfectly straightforward. To proceed further, it is thus necessary to determine the transformation properties of irreducible tensors under the symmetry operations of the point group appropriate for any particular molecule.

The first stage involves mapping the irreducible representations of the full threedimensional rotation-inversion group $0(3)$ onto the corresponding representations of point groups with lower symmetry. Although the procedure is outlined by SALTHOUSE and WARE [9] and certain results have been given by STEDMAN [10] a complete listing for all the common molecular and crystallographic point groups does not appear to be available in the literature. The necessary results are given in Appendix 1, in which irreducible representations $D^{(j \pm)}$ for weights $j=0-4$ are given for both even and odd parity. Taking the case of the tetrahedral point group $T_{d}$ as an illustration, Tables 2 and 3 provide a comparison of the information on transformation properties contained in the standard character table and the corresponding irreducible representation table of Appendix 1.

Table 2. Irreducible representations of rotations, translations and products of translations in the point group $T_{d}$

\begin{tabular}{|c|c|c|c|c|c|}
\hline$A_{1}$ & $x^{2}+y^{2}+z^{2}$ & & & & \\
\hline $\begin{array}{l}A_{2} \\
E \\
T_{1}\left(R_{\mathrm{x}}, R_{\mathrm{y}}, R_{z}\right) \\
T_{2}(\mathrm{x}, \mathrm{y}, \mathrm{z})\end{array}$ & $\begin{array}{l}\left(2 z^{2}-x^{2}-y^{2}, x^{2}-y^{2}\right) \\
(x y, x z, y z)\end{array}$ & $\begin{array}{l}{\left[x\left(z^{2}-y^{2}\right),\right.} \\
\left(x^{3}, y^{3}, z^{3}\right)\end{array}$ & $\begin{array}{l}y\left(z^{2}-x^{2}\right), \\
{\left[x\left(z^{2}+y^{2}\right),\right.}\end{array}$ & $\begin{array}{l}\left.z\left(x^{2}-y^{2}\right)\right] \\
y\left(z^{2}+x^{2}\right)\end{array}$ & $\left.z\left(x^{2}+y^{2}\right)\right]$ \\
\hline
\end{tabular}


Table 3. Representations of irreducible tensors in the point group $T_{d}$. (Even parity representations are denoted by Roman characters and odd parity by italic characters)

\begin{tabular}{lllll}
\hline $\mathrm{D}^{(0+)}$ & $\mathrm{D}^{(1+)}$ & $\mathrm{D}^{(2+)}$ & $\mathrm{D}^{(3+)}$ & $\mathrm{D}^{(4+)}$ \\
$D^{(0-)}$ & $D^{(1-)}$ & $D^{(2-)}$ & $D^{(3-)}$ & $D^{(4-)}$ \\
\hline $\mathrm{A}_{1}$ & $\mathrm{~T}_{1}$ & $\mathrm{E}+\mathrm{T}_{2}$ & $\mathrm{~A}_{2}+\mathrm{T}_{1}+\mathrm{T}_{2}$ & $\mathrm{~A}_{1}+\mathrm{E}+\mathrm{T}_{1}+\mathrm{T}_{2}$ \\
$A_{2}$ & $T_{2}$ & $E+T_{1}$ & $A_{1}+T_{1}+T_{2}$ & $A_{2}+E+T_{1}+T_{2}$ \\
\hline
\end{tabular}

Several points are worth noting. In the electric dipole approximation, the coupling of $n$ photons is associated with a rank $n$ molecular tensor of parity $(-1)^{n}$, i.e. the parity has the odd or even character of $n$ itself. Thus, for example, conventional single-photon absorption is associated with the representation $D^{(1-)}$ of an odd parity rank 1 tensor like a translation vector, whilst two-photon processes are normally associated with an even parity second rank tensor $T_{2}$, for which in the general case the appropriate irreducible representations are $D^{(0+)}, D^{(1+)}$ and $D^{(2+)}$. Although Table 3 clearly contains no information on the the transformation properties of individual tensor components, these in fact prove to be redundant for many kinds of symmetry analysis, such as those to be discussed in later sections. Table 3 and its counterparts in Appendix 1 have the advantage of containing information on the transformation properties of ten types of irreducible tensor (five weights, $j=0-4$, each with either odd or even parity). By contrast the familiar symmetry tables like Table 2 offer information only on $D^{(1 \pm)}$ in column 1 , with a mixture of $D^{(0+)}$ and $D^{(2+)}$ in column 2 and a mixture of $D^{(1-)}$ and $D^{(3-)}$ in column 3 (if present).

For application to high order multiphoton processes the most significant point is the fact that the components of the appropriate rank $n$ molecular tensors in general do not have the same transformation properties as the product of $n$ equivalent translation vector components, since these products are necessarily associated with full index symmetry. Thus, for example, in the case of hyper-Raman scattering, the third rank (hyperpolarizability) tensor involved, which is of the type $T_{1(2)}$ since the two absorbed photons are identical, possesses contributions of character $D^{(1-)}, D^{(2-)}$ and $D^{(3-)}$ as Table 1 shows. The familiar association of column 2 in tables like Table 2 with Raman activity tempts a casual reader to associate column 3 with hyper-Raman activity, leading to the incorrect conclusion that $E$ modes, for example, are hyper-Raman inactive.

One final point illustrated by Table 3 is that it is a relatively simple matter to extend the description of multiphoton effects to include contributions from higher order multipoles. For example two-photon transitions which are weakly allowed by coupling one electric dipole (odd parity) and one magnetic dipole (even parity) interaction are described by a second rank response tensor $T_{2}$ of odd parity, represented by $D^{(0-)}, D^{(1-)}$ and $D^{(2-)}$. Electric quadrupole effects are incorporated by noting that each such interaction is associated with an even parity representation carrying weights 0 and 2 . Thus the coupling of one electric dipole and one electric quadrupole interaction is represented by a polar third rank tensor of the form $T_{1(2)}$, for which the irreducible representations are $D^{(1-)}, D^{(2-)}$ and $D^{(3-)}$, as shown by Table 1 . Whilst such interactions might appear esoteric, they nonetheless play an important role in chiral discrimination, as, for example, in Raman optical activity [11].

\section{Symmetry Classification of Multiphoton Transitions}

Examination of the tables in Appendix 1 reveals that for each irreducible representation of each point group there are certain combinations of tensor weights which may be non-zero. This can again be illustrated by reference to the point group $T_{d}$. Consider the case of three-beam three-photon absorption, for which the molecular response tensor $T_{3}$ in general has contributions from weights $j=0,1,2$ and 3 , all with odd parity (in the 
electric dipole approximation). However, since $A_{1}$, for example, appears only in the weight 3 column of odd parity representations in Table 3 , it transpires that for transitions to excited states with this symmetry, only weight 3 contributions are in fact permitted by the selection rules, as the remarks at the beginning of Section 4 explain. In the case of three-photon transitions to an $A_{2}$ state, by contrast, only weight 0 contributions are allowed.

The question of which tensor weights are permitted under multiphoton selcction rules has a powerful influence in determining polarization behaviour. In many cases this is dramatically evident when certain spectral lines are observed to disappear from a multiphoton spectrum under particular conditions. Consequently, it is helpful to classify each potential excited state in terms of the combination of allowed weights in tensors of each rank and parity. Table 4 illustrates the full results for molecules of $T_{d}$ symmetry. For example, from the column headed rank 3 , odd parity, it is evident that in three-beam three-photon spectroscopy all transitions are in principle allowed, and each excited state symmetry class is associated with a different combination of weights. This means that suitably chosen polarization conditions will in fact allow the complete and unambiguous symmetry classification of every line in the spectrum. By contrast, the entries under the heading of rank 2, even parity, show that in two-photon spectroscopy, transitions to excited states of symmetry $\boldsymbol{A}_{2}$ are forbidden and polarization studies cannot differentiate between the polarization behaviour of $E$ and $T_{2}$ transitions since they both carry the same weights. A complete listing of such tables for all the common point groups is provided in Appendix 2.

Table 5 provides a complete listing of the various distinguishable symmetry classes which actually arise for two-, three- and four-photon processes in molecules belonging to

Table 4. Weights allowed under the irreducible representations of the point group $T_{d}$ in response tensors up to rank four

\begin{tabular}{lrrrrrrrr}
\hline & \multicolumn{2}{c}{ Rank 1 } & \multicolumn{2}{c}{ Rank 2 } & \multicolumn{2}{c}{ Rank 3 } & \multicolumn{2}{c}{ Rank 4 } \\
Parity & + & - & + & - & + & \multicolumn{1}{c}{+} & \\
\hline$A_{1}$ & & & $(0)$ & & $(0)$ & $(3)$ & $(04)$ & $(3)$ \\
$A_{2}$ & & & & $(0)$ & $(3)$ & $(0)$ & $(3)$ & $(04)$ \\
$E$ & & & $(2)$ & $(2)$ & $(2)$ & $(2)$ & $(24)$ & $(24)$ \\
$T_{1}$ & $(1)$ & & $(1)$ & $(2)$ & $(13)$ & $(23)$ & $(134)$ & $(234)$ \\
$T_{2}$ & & $(1)$ & $(2)$ & $(1)$ & $(23)$ & $(13)$ & $(234)$ & $(134)$ \\
\hline
\end{tabular}

Table 5. Symmetry classes which arise in the common molecular point groups for two-, three- and four-photon processes, with typical examples (irreducible representation/point group)

\begin{tabular}{|c|c|c|c|c|c|}
\hline \multicolumn{2}{|c|}{ Two photons } & \multicolumn{2}{|c|}{ Three photons } & \multicolumn{2}{|c|}{ Four photons } \\
\hline Class & Example & Class & Example & Class & Example \\
\hline $\begin{array}{l}2^{+}(012) \\
2^{+}(12) \\
2^{+}(02) \\
2^{+}(2) \\
2^{+}(1) \\
2^{+}(0)\end{array}$ & $\begin{array}{l}A / C_{1} \\
A_{2} / C_{2 v} \\
A_{1} / C_{2 v} \\
E^{\prime} / \mathrm{D}_{3 h} \\
\mathrm{~A}_{2} / D_{3 h} \\
A_{1} / T_{d}\end{array}$ & $\begin{array}{l}3^{-}(0123) \\
3^{-}(123) \\
3^{-}(023) \\
3^{-}(23) \\
3^{-}(13) \\
3^{-}(03) \\
3^{-}(02) \\
3^{-}(3) \\
3^{-}(2) \\
3^{-}(1) \\
3^{-}(0)\end{array}$ & $\begin{array}{l}A / C_{1} \\
\Pi / C_{\infty u} \\
A_{1 u} / D_{3 d} \\
T_{2 u} / O_{h} \\
T_{1 u} / O_{h} \\
A / T \\
\Sigma^{-} / C_{\infty^{\prime}} \\
A_{2 u} / O_{h} \\
E_{u} / O_{h} \\
T_{1} / I \\
A_{1 u} / O_{h}\end{array}$ & $\begin{array}{l}4^{+}(01234) \\
4^{+}(1234) \\
4^{+}(0234) \\
4^{+}(234) \\
4^{+}(134) \\
4^{+}(034) \\
4^{+}(024) \\
4^{+}(34) \\
4^{+}(24) \\
4^{+}(13) \\
4^{+}(04) \\
4^{+}(4) \\
4^{+}(3) \\
4^{+}(1) \\
4^{+}(0)\end{array}$ & $\begin{array}{l}A / C_{1} \\
E_{1 g} / D_{6 h} \\
A_{1} / C_{2 b} \\
E_{2}^{\prime} / D_{5 h} \\
A_{2} / C_{3 \mathrm{v}} \\
A / T \\
A_{1 g} / D_{6 h} \\
A^{\prime \prime} / C_{3 h} \\
E_{g} / T_{d} \\
A_{2} / C_{5 b} \\
A_{1} / T_{d} \\
E_{1}^{\prime} / D_{5 h} \\
A_{2} / T_{d} \\
T_{1 g} / I_{h} \\
A_{g} / I_{h}\end{array}$ \\
\hline
\end{tabular}


the common point groups, with examples of each class. For example, in the case of twophoton absorption or Raman scattering there are six classes: (i) weights 0,1 and 2 present; (ii) weights 1 and 2 alone; (iii) weights 0 and 2 alone; (iv) weight 2 alone; (v) weight 1 alone; and (vi) weight 0 alone present. For three-photon processes there are eleven such classes. Since four of these have the same combination of weights as the last four classes of two-photon absorption, a suitable designation of such classes must include labels for the tensor rank and parity. It is therefore proposed to introduce symmetry class labels defined as $n^{ \pm}\left(j_{i}\right)$, where $j_{i}$ represents the allowed weights placed in ascending order. For example class (iii) of two-photon absorption is represented by $2^{+}(02)$, whilst the corresponding class of three-photon absorption where only weights 0 and 2 are present is designated $3^{-}(02)$.

Where index symmetry conditions in either the radiation tensor or the molecular tensor result in the exclusion of certain weights, as discussed in Sections 3.1 and 3.2, then certain of these classes may become forbidden and the polarization distinguishability of others will disappear. For example, in non-resonance Raman scattering, the approximate index symmetry in the molecular tensor means that weight 1 contributions vanish. Thus the class $2^{+}(1)$ becomes forbidden, and classes $2^{+}(012)$ and $2^{+}(02)$ become indistinguishable, as do classes $2^{+}(12)$ and $2^{+}(2)$. As a result there are only three distinguishable groupings of Raman-allowed transitions, which correspond to lines which are fully polarized (class $2^{+}(0)$ where $\left.\rho=0\right)$, depolarized (classes ${ }^{+}(012)$ and $2^{+}(02)$ where $\rho<\frac{3}{4}$ ) and fully depolarized (classes $2^{+}(12)$ and $2^{+}(2)$ where $\rho=\frac{3}{4}$ ). Whilst this behaviour is well-known, the corresponding sixfold symmetry classification of vibrations active in resonance Raman spectroscopy appears to be less familiar.

In the hyper-Raman effect the molecular tensor form is $T_{1(2)}$ which, as shown by reference to Table 1, carries (odd parity) weights 1,2 and 3 . It is therefore immediately clear that, as Table 7 shows, class $3^{-}(0)$ is forbidden and the other allowed classes fall into six groupings: (i) classes $3^{-}(0123)$ and $3^{-}(123)$; (ii) classes $3^{-}(023)$ and $3^{-}(23)$; (iii) class $3^{-}(13)$; (iv) classes $3^{-}(03)$ and $3^{-}(3)$; (v) classes $3^{-}(02)$ and $3^{-}(2)$; and (vi) class $3^{-}(1)$. These correspond to classes $A-F$ in the early study by ANDREws and THIRUNAMACHANDRAN [4] in which it was shown how a suitable choice of five polarization configurations enables each hyper-Raman active vibration to be unambiguously assigned to one of these six groupings. In many cases this can lead to an irreducible symmetry assignment through use of tables such as those given in Appendix 2.

Similar arguments apply to the common cases of multiphoton absorption where two or more of the absorbed photons have the same frequency. For historical reasons, classification schemes were first introduced for the experimentally simpler single-beam cases [12] and subsequently modified for double-beam [13,14] and multiple-beam applications [15]. Once again, with the benefit of hindsight it is obvious that the old schemes are somewhat less than ideal and the proposed new method of classification should not only be clearer in its physical meaning, but also less likely to be confused with other symmetry designations and more readily adapted to cases where index symmetry arises. Tables $6-8$ provide the necessary correlations between the old and new classification schemes.

\section{Characterization of Multiphoton Transitions by Polarization analysis}

A detailed study of the dependence of multiphoton transition rates on polarization and beam geometry falls outside the scope of this paper and has received extensive treatment elsewhere, particularly in the review by STEDMAN [10]. However, it is appropriate to illustrate methods by which suitable polarization configurations can be chosen to increase the amount of information available from multiphoton spectra. This invariably exceeds the content of the data obtained by non-selective laser excitation, in most cases to a considerable extent, as was first demonstrated by MCCLAIN [16,17]. The methods adopted here also enable some of the potentially misleading aspects of multiphoton excitation to be highlighted. 
Table 6. Correlation of general symmetry classes for twophoton processes with an earlier classification scheme [12] for single-beam two-photon absorption

\begin{tabular}{llllll}
\hline $2^{+}(012)$ & Class I & $2^{+}(02)$ & Class I & $2^{+}(1)$ & - \\
$2^{+}(12)$ & Class II & $2^{+}(2)$ & Class II & $2^{+}(0)$ & Class III
\end{tabular}

Table 7. Correlation of general symmetry classes for three-photon processes with earlier classification schemes appropriate for singlebeam $\left(T_{(3)}\right)$, double-beam $\left(T_{1(2)}\right)$ and triple-beam $\left(T_{3}\right)$ absorption [12-15]

\begin{tabular}{llllllll}
\hline & $T_{(3)}$ & $T_{1(2)}$ & $T_{3}$ & & $T_{(3)}$ & $T_{1(2)}$ & $T_{3}$ \\
\hline $3^{-}(0123)$ & I & IA & IA $^{\prime}$ & $3^{-}(02)$ & - & IV & IV $^{\prime}$ \\
$3^{-}(123)$ & I & IA & IA & $3^{-}(3)$ & II & IIB & IIB \\
$3^{-}(023)$ & II & IIA & IIA $^{\prime}$ & $3^{-}(2)$ & - & IV & IV \\
$3^{-}(23)$ & II & IIA & IIA & $3^{-}(1)$ & III & III & III \\
$3^{-}(13)$ & I & IB & IB & $3^{-}(0)$ & - & - & V \\
$3^{-}(03)$ & II & IIB & IIB' & & & & \\
\hline
\end{tabular}

Table 8. Correlation of general symmetry classes for four-photon processes with an earlier classification scheme [12] for single-beam four-photon absorption.

\begin{tabular}{llllll}
\hline $4^{+}(01234)$ & I & $4^{+}(034)$ & III & $4^{+}(04)$ & III \\
$4^{+}(1234)$ & II & $4^{+}(024)$ & I & $4^{+}(4)$ & IV \\
$4^{+}(0234)$ & I & $4^{+}(34)$ & IV & $4^{+}(3)$ & - \\
$4^{+}(234)$ & II & $4^{+}(24)$ & II & $4^{+}(1)$ & - \\
$4^{+}(134)$ & IV & $4^{+}(13)$ & - & $4^{+}(0)$ & V \\
\hline
\end{tabular}

The question of whether a given transition is allowed in a given polarization configuration is determined by whether or not the irreducible parts of the radiation tensor have one or more weights in common with permitted weights of the molecular tensor: otherwise every term in the $j$ summation of Eqn (5) must be zero and the transition is therefore forbidden. Application of this rule can most simply be illustrated by reference to Raman scattering, where the radiation tensor $S_{2}$ in general carries weights $j=0,1$ and 2 . However, not all these weights are in fact represented in every polarization configuration.

For example, in the polarized Raman spectrum, obtained by collecting scattered photons with linear polarization parallel to that of the laser photons, weight 1 is absent and in the same way weight 0 is absent from the depolarized Raman spectrum. The latter condition is manifest in the familiar fact that pure weight 0 transitions, such as those involving totally symmetric vibrations in molecules belonging to one of the cubic or icosahedral point groups, are forbidden in depolarized Raman scattering and are thus associated with depolarization ratios of zero.

In considering higher order multiphoton processes, two general rules emerge. First, it is always the case that an $n$-photon radiation tensor lacks weight $j=(n-1)$ if the polarization vectors of all photons are identical, at least within the electric dipole approximation. Secondly, in the special case where all photons propagate in the same direction and have effectively the same circular polarization, all weights $j<n$ are forbidden. For scattering processes where the scattered photon is emitted in the forward direction, these remarks have to be interpreted as a requirement that the complex conjugate of the polarization vector for the emitted photon is the same as the polarization vector for the incident photons. When the incident light is circularly polarized, the condition thus applies to emission with helicity reversal. 
Interesting features arise in the case of hyper-Raman scattering, where the appropriate radiation tensor $S_{1(2)}$ in general carries the same weights as the molecular tensor $T_{1(2)}$, i.e. $j=1,2$ and 3 , but once again not all weights are necessarily represented in every polarization condition. This has a crucial bearing on considerations of the index symmetry properties of the molecular hyper-Raman tensor. Whilst the earliest theories of the process $[18,19]$ were based on an assumption of full index symmetry $\left(T_{(3)}\right.$, weights 1 and 3), later studies [20] showed that the correct formulation involves only pair index symmetry $\left(T_{1(2)}\right.$, weights 1,2 and 3$)$. Experimental evidence for the distinction can, however, only be expected in polarization conditions which allow observation of weight 2 behaviour. Since the $(n-1)$ rule results in weight 2 being excluded from any polarized hyper-Raman spectrum, it is not surprising that experimental proof for the $T_{1(2)}$ structure has not been forthcoming [21]. There nonetheless remains no case for assuming the molecular tensor to be fully index symmetric [22].

A final, and rather more exotic, illustration is afforded by one of the more curious aspects of four-photon absorption. With counter-propagating beams of opposite circular polarization, then since the polarization vector for a circularly polarized photon travelling in the $\hat{k}$ direction is the same as that for a photon of opposite helicity travelling in the $-\hat{k}$ direction, all photons present have effectively the same polarization vector. The second general polarization rule given above thus shows that in four-photon absorption, only weight 4 can be represented in the spectrum. Thus, transitions to totally symmetric excited states in icosahedral molecules, being of class $4^{+}(0)$, are forbidden. However, with counter-propagating beams of equal circular polarization, it transpires that weight 0 contributions can only arise if two photons are absorbed from each beam [23]. The result is the appearance of a totally Doppler-free line in the four-photon spectrum. This feature uniquely characterizes icosahedral symmetry and could thus prove significant in the characterization of Buckminsterfullerene and similar species.

\section{REFERENCES}

[1] M. Göppert-Mayer, Ann. Phys. 9, 273 (1931).

[2] W. Kaiser and C. G. B. Garrett, Phys. Rev. Lett. 7, 229 (1961).

[3] J. Jerphagnon, Phys. Rev. B 2, 1091 (1970).

[4] D. L. Andrews and T. Thirunamachandran, J. Chem. Phys. 68, 2941 (1978).

[5] D. L. Andrews and W. A. Ghoul, Phys. Rev. A 25, 2647 (1982).

[6] I. M. Gel'fand, R. A. Minlos and Z. Ya. Shapiro, Representations of the Rotation and Lorentz Groups and their Applications. Pergamon Press, Oxford (1963).

[7] V. V. Mikhailov, J. Phys. A 10, 147 (1977).

[8] S. F. A. Kettle, Symmetry and Structure. Wiley, New York (1985).

[9] J. A. Salthouse and M. J. Ware, Point Group Character Tables. Cambridge University Press, Cambridge (1972).

[10] G. E. Stedman, Adv. Phys. 34, 513 (1985).

[11] L. D. Barron, Molecular Light Scattering and Optical Activity. Cambridge University Press, Cambridge (1982).

[12] D. L. Andrews and W. A. Ghoul, J. Chem. Phys. 75, 530 (1981).

[13] D. L. Andrews, J. Chem. Phys. 77, 2831 (1982).

[14] D. L. Andrews, J. Chem. Phys. 78, 1731 (1983).

[15] D. L. Andrews and P. J. Wilkes, J. Chem. Phys. 83, 2009 (1985).

[16] W. M. McClain, J. Chem. Phys. 55, 2789 (1971).

[17] W. M. McClain, J. Chem. Phys. 57, 2264 (1972).

[18] S. J. Cyvin, J. E. Rauch and J. C. Decius, J. Chem. Phys. 43, 4083 (1965).

[19] L. Stanton, Molec. Phys. 23, 601 (1972).

[20] J. H. Christie and D. J. Lockwood, J. Chem. Phys. 54, 1141 (1971).

[21] D. L. Andrews, Molec. Phys. 37, 325 (1979).

[22] V. N. Denisov, B. N. Mavrin and V. B. Podobedov, Phys. Rept. 151, 1 (1987).

[23] D. L. Andrews and K. P. Hopkins, Chem. Phys. Letts 146, 37 (1988). 
APPENDIX 1 Representations of irreducible tensors in the common molecular and crystallographic point groups (even parity representations are denoted by Roman characters and odd parity by italic characters)

\begin{tabular}{|c|c|c|c|c|c|}
\hline $\begin{array}{l}\text { Point } \\
\text { group }\end{array}$ & $\begin{array}{l}D^{(0+)} \\
D^{(0-)}\end{array}$ & $\begin{array}{l}\mathrm{D}^{(1+)} \\
D^{(l-)}\end{array}$ & $\begin{array}{l}\mathrm{D}^{(2+)} \\
D^{(2-)}\end{array}$ & $\begin{array}{l}D^{(3+)} \\
D^{(3-)}\end{array}$ & $\begin{array}{l}\mathrm{D}^{(4+)} \\
D^{(4-)}\end{array}$ \\
\hline \multirow[t]{2}{*}{$C_{1}$} & $\mathbf{A}$ & $\mathbf{A}$ & $\mathbf{A}$ & $\mathbf{A}$ & $\mathbf{A}$ \\
\hline & $A$ & $A$ & $\boldsymbol{A}$ & $A$ & $A$ \\
\hline \multirow[t]{2}{*}{$C_{i}$} & $\mathbf{A}_{\mathbf{g}}$ & $\mathbf{A}_{8}$ & $\mathbf{A}_{\mathbf{g}}$ & $A_{B}$ & $\mathbf{A}_{\mathrm{g}}$ \\
\hline & $A_{u}$ & $A_{u}$ & $\boldsymbol{A}_{\mu}$ & $A_{u}$ & $A_{u}$ \\
\hline \multirow[t]{2}{*}{$C_{\mathrm{s}}$} & $A^{\prime}$ & $A^{\prime}+2 A^{\prime \prime}$ & $3 A^{\prime}+2 A^{\prime \prime}$ & $3 A^{\prime}+4 A^{\prime \prime}$ & $5 A^{\prime}+4 A^{\prime \prime}$ \\
\hline & $A^{\prime \prime}$ & $2 A^{\prime}+A^{\prime \prime}$ & $2 A^{\prime}+3 A^{\prime \prime}$ & $4 A^{\prime}+3 A^{\prime \prime}$ & $4 A^{\prime}+5 A^{\prime \prime}$ \\
\hline \multirow[t]{2}{*}{$C_{2}$} & A & $A+2 B$ & $3 A+2 B$ & $3 A+4 B$ & $5 A+4 B$ \\
\hline & $A$ & $A+2 B$ & $3 A+2 B$ & $3 A+4 B$ & $5 A+4 B$ \\
\hline \multirow[t]{2}{*}{$C_{3}$} & A & $\mathbf{A}+\mathbf{E}$ & $A+2 E$ & $3 A+2 E$ & $3 A+3 E$ \\
\hline & $A$ & $A+E$ & $A+2 E$ & $3 A+2 E$ & $3 A+3 E$ \\
\hline \multirow[t]{2}{*}{$C_{4}$} & $\mathbf{A}$ & $A+E$ & $A+2 B+E$ & $A+2 B+2 E$ & $3 \mathrm{~A}+2 \mathrm{~B}+2 \mathrm{E}$ \\
\hline & $A$ & $A+E$ & $A+2 B+E$ & $A+2 B+2 E$ & $3 A+2 B+2 E$ \\
\hline \multirow[t]{2}{*}{$C_{5}$} & A & $A+E_{1}$ & $A+E_{1}+E_{2}$ & $A+E_{1}+2 E_{2}$ & $\mathrm{~A}+2 \mathrm{E}_{1}+2 \mathrm{E}_{2}$ \\
\hline & $A$ & $A+E_{I}$ & $A+E_{1}+E_{2}$ & $A+E_{1}+2 E_{2}$ & $A+2 E_{1}+2 E_{2}$ \\
\hline \multirow[t]{2}{*}{$C_{6}$} & $\mathbf{A}$ & $A+E_{1}$ & $A+E_{1}+E_{2}$ & $A+2 B+E_{1}+E_{2}$ & $\mathrm{~A}+2 \mathrm{~B}+\mathrm{E}_{1}+2 \mathrm{E}_{2}$ \\
\hline & $A$ & $A+E_{l}$ & $A+E_{1}+E_{2}$ & $A+2 B+E_{1}+E_{2}$ & $A+2 B+E_{1}+2 E_{2}$ \\
\hline \multirow[t]{2}{*}{$S_{4}$} & A & $A+E$ & $A+2 B+E$ & $A+2 B+2 E$ & $3 \mathrm{~A}+2 \mathrm{~B}+2 \mathrm{E}$ \\
\hline & $B$ & $B+E$ & $2 A+B+E$ & $2 A+B+2 E$ & $2 A+3 B+2 E$ \\
\hline$S_{6}$ & $\begin{array}{l}\mathrm{A}_{\mathrm{z}} \\
A_{\mathrm{u}}\end{array}$ & $\begin{array}{l}\mathrm{A}_{\mathrm{g}}+\mathrm{E}_{\mathrm{g}} \\
A_{u}+E_{u}\end{array}$ & $\begin{array}{l}\mathrm{A}_{\mathrm{g}}+2 \mathrm{E}_{\mathrm{g}} \\
A_{u}+2 E_{u}\end{array}$ & $\begin{array}{l}3 A_{g}+2 E_{g} \\
3 A_{u}+2 E_{u}\end{array}$ & $\begin{array}{l}3 \mathrm{~A}_{\mathrm{g}}+3 \mathrm{E}_{\mathrm{g}} \\
3 A_{u}+3 E_{u}\end{array}$ \\
\hline$S_{8}$ & $\begin{array}{l}\mathbf{A} \\
B\end{array}$ & $\begin{array}{l}A+E_{3} \\
B+E_{1}\end{array}$ & $\begin{array}{l}\mathrm{A}+\mathrm{E}_{2}+\mathrm{E}_{3} \\
B+E_{1}+E_{2}\end{array}$ & $\begin{array}{l}\mathrm{A}+\mathrm{E}_{1}+\mathrm{E}_{2}+\mathrm{E}_{3} \\
B+E_{1}+E_{2}+E_{3}\end{array}$ & $\begin{array}{l}\mathrm{A}+2 \mathrm{~B}+\mathrm{E}_{1}+\mathrm{E}_{2}+\mathrm{E}_{3} \\
2 A+B+E_{l}+E_{2}+E_{3}\end{array}$ \\
\hline$s_{10}$ & $\begin{array}{l}\mathrm{A}_{\mathrm{g}} \\
\boldsymbol{A}_{\mathrm{u}}\end{array}$ & $\begin{array}{l}\mathrm{A}_{\mathrm{g}}+\mathrm{E}_{1 \mathrm{~g}} \\
A_{\mathrm{u}}+E_{\mathrm{Iu}}\end{array}$ & $\begin{array}{l}A_{g}+E_{1 g}+E_{2 g} \\
A_{u}+E_{l u}+E_{2 u}\end{array}$ & $\begin{array}{l}B+E_{l}+E_{2}+E_{3} \\
\mathrm{~A}_{\mathrm{g}}+\mathrm{E}_{1 \mathrm{~g}}+2 \mathrm{E}_{2 \mathrm{~g}} \\
A_{u}+E_{l u}+2 E_{2 u}\end{array}$ & $\begin{array}{l}2 A+B+E_{l}+E_{2}+E_{3} \\
\mathrm{~A}_{\mathrm{g}}+2 \mathrm{E}_{1 \mathrm{~g}}+2 \mathrm{E}_{2 \mathrm{~g}} \\
\mathrm{~A}_{u}+2 E_{1 \mathrm{u}}+2 E_{2 u}\end{array}$ \\
\hline$c_{2 h}$ & $\begin{array}{l}\mathbf{A}_{8} \\
A_{u}\end{array}$ & $\begin{array}{l}\mathrm{A}_{\mathrm{B}}+2 \mathrm{~B}_{\mathrm{g}} \\
A_{u}+2 B_{u}\end{array}$ & $\begin{array}{l}3 A_{g}+2 B_{g} \\
3 A_{u}+2 B_{u}\end{array}$ & $\begin{array}{l}3 \mathrm{~A}_{\mathrm{g}}+4 \mathrm{~B}_{\mathrm{g}} \\
3 A_{u}+4 B_{u}\end{array}$ & $\begin{array}{l}5 A_{g}+4 B_{g} \\
5 A_{u}+4 B_{u}\end{array}$ \\
\hline \multirow[t]{2}{*}{$C_{3 h}$} & $\mathbf{A}^{\prime}$ & $\mathbf{A}^{\prime}+\mathbf{E}^{\prime \prime}$ & $\mathrm{A}^{\prime}+\mathrm{E}^{\prime}+\mathrm{E}^{\prime \prime}$ & $A^{\prime}+2 A^{\prime \prime}+E^{\prime}+E^{\prime \prime}$ & $A^{\prime}+2 A^{\prime \prime}+2 E^{\prime}+E^{\prime \prime}$ \\
\hline & $A^{\prime \prime}$ & $A^{\prime \prime}+E^{\prime}$ & $A^{\prime \prime}+E^{\prime}+E^{\prime \prime}$ & $2 A^{\prime}+A^{\prime \prime}+E^{\prime}+E^{\prime \prime}$ & $2 A^{\prime}+A^{\prime \prime}+E^{\prime}+2 E^{\prime \prime}$ \\
\hline$C_{\text {4h }}$ & $\begin{array}{l}\mathrm{A}_{\mathrm{g}} \\
\boldsymbol{A}_{u}\end{array}$ & $\begin{array}{l}\mathrm{A}_{\mathrm{g}}+\mathrm{E}_{\mathrm{g}} \\
A_{\mathrm{u}}+E_{\mathrm{u}}\end{array}$ & $\begin{array}{l}A_{g}+2 B_{g}+E_{g} \\
A_{u}+2 B_{u}+E_{u}\end{array}$ & $\begin{array}{l}\mathrm{A}_{\mathrm{g}}+2 \mathrm{~B}_{\mathrm{g}}+2 \mathrm{E}_{\mathrm{g}} \\
A_{u}+2 B_{u}+2 E_{u}\end{array}$ & $\begin{array}{l}3 A_{g}+2 B_{g}+2 E_{g} \\
3 A_{u}+2 B_{u}+2 E_{u}\end{array}$ \\
\hline$C_{5 h}$ & $\mathbf{A}^{\prime}$ & $\mathrm{A}^{\prime}+\mathrm{E}_{1}^{\prime \prime}$ & $A^{\prime}+E_{1}^{\prime \prime}+E_{2}^{\prime}$ & $A^{\prime}+E_{1}^{\prime \prime}+E_{2}^{\prime}+E_{2}^{\prime \prime}$ & $A^{\prime}+E_{1}^{\prime}+E_{1}^{\prime \prime}+E_{2}^{\prime}+E_{2}^{\prime \prime}$ \\
\hline & $A^{\prime \prime}$ & $A^{n}+E_{l}^{\prime}$ & $A^{\prime \prime}+E_{1}^{\prime}+E_{2}^{\prime \prime}$ & $A^{\prime \prime}+E_{1}^{\prime}+E_{2}^{\prime}+E_{2}^{\prime \prime}$ & $A^{\prime \prime}+E_{1}^{\prime}+E_{1}^{\prime \prime}+E_{2}^{\prime}+E_{2}^{\prime \prime}$ \\
\hline$C_{6 h}$ & $\begin{array}{l}\mathbf{A}_{\mathrm{B}} \\
\boldsymbol{A}_{u}\end{array}$ & $\begin{array}{l}\mathrm{A}_{\mathrm{g}}+\mathrm{E}_{1 \mathrm{~g}} \\
A_{\mathrm{u}}+E_{l u}\end{array}$ & $\begin{array}{l}A_{\mathrm{g}}+E_{1 \mathrm{~g}}+\mathrm{E}_{2 \mathrm{~g}} \\
A_{u}+E_{l u}+E_{2 u}\end{array}$ & $\begin{array}{l}\mathrm{A}_{\mathrm{g}}+2 \mathrm{~B}_{\mathrm{g}}+\mathrm{E}_{1 \mathrm{~g}}+\mathrm{E}_{2 \mathrm{~g}} \\
A_{u}+2 B_{u}+E_{l u}+E_{2 u}\end{array}$ & $\begin{array}{l}\mathrm{A}_{\mathrm{g}}+2 \mathrm{~B}_{\mathrm{g}}+\mathrm{E}_{1 \mathrm{~g}}+2 \mathrm{E}_{2 \mathrm{~g}} \\
A_{\mathrm{u}}+2 B_{u}+E_{l u}+2 E_{2 u}\end{array}$ \\
\hline$c_{2 v}$ & $A_{1}$ & $A_{2}+B_{1}+B_{2}$ & $2 \mathbf{A}_{1}+\mathbf{A}_{2}+\mathbf{B}_{1}+\mathbf{B}_{2}$ & $A_{1}+2 A_{2}+2 B_{1}+2 B_{2}$ & $3 A_{1}+2 A_{2}+2 B_{1}+2 B_{2}$ \\
\hline & $A_{2}$ & $A_{1}+B_{1}+B_{2}$ & $A_{1}+2 A_{2}+B_{1}+B_{2}$ & $2 A_{1}+A_{2}+2 B_{1}+2 B_{2}$ & $2 A_{1}+3 A_{2}+2 B_{1}+2 B_{2}$ \\
\hline$C_{3 v}$ & $\mathbf{A}_{1}$ & $A_{2}+E$ & $A_{1}+2 E$ & $A_{1}+2 A_{2}+2 E$ & $2 A_{1}+A_{2}+3 E$ \\
\hline & $A_{2}$ & $A_{1}+E$ & $A_{2}+2 E$ & $2 A_{1}+A_{2}+2 E$ & $A_{1}+2 A_{2}+3 E$ \\
\hline$C_{4 v}$ & $\mathbf{A}_{1}$ & $A_{2}+E$ & $A_{1}+B_{1}+B_{2}+E$ & $A_{2}+B_{1}+B_{2}+2 E$ & $2 A_{1}+A_{2}+B_{1}+B_{2}+2 E$ \\
\hline & $A_{2}$ & $A_{I}+E$ & $A_{2}+B_{1}+B_{2}+E$ & $A_{l}+B_{1}+B_{2}+2 E$ & $A_{1}+2 A_{2}+B_{1}+B_{2}+2 E$ \\
\hline$C_{5 v}$ & $\mathbf{A}_{1}$ & $A_{2}+E_{1}$ & $A_{1}+E_{1}+E_{2}$ & $A_{2}+E_{1}+2 E_{2}$ & $A_{1}+2 E_{1}+2 E_{2}$ \\
\hline & $A_{2}$ & $A_{1}+E_{l}$ & $A_{2}+E_{1}+E_{2}$ & $A_{1}+E_{1}+2 E_{2}$ & $A_{2}+2 E_{1}+2 E_{2}$ \\
\hline$C_{60}$ & $\mathbf{A}_{1}$ & $A_{2}+E_{1}$ & $A_{1}+E_{1}+E_{2}$ & $A_{2}+B_{1}+B_{2}+E_{1}+E_{2}$ & $A_{1}+B_{1}+B_{2}+E_{1}+2 E_{2}$ \\
\hline & $A_{2}$ & $A_{3}+E_{l}$ & $A_{2}+E_{1}+E_{2}$ & $A_{1}+B_{1}+B_{2}+E_{1}+E_{2}$ & $A_{2}+B_{1}+B_{2}+E_{1}+2 E_{2}$ \\
\hline$D_{2}$ & $\mathbf{A}$ & $\mathbf{B}_{1}+\mathbf{B}_{2}+\mathbf{B}_{3}$ & $2 A+B_{1}+B_{2}+B_{3}$ & $A+2 B_{1}+2 B_{2}+2 B_{3}$ & $3 \mathrm{~A}+2 \mathrm{~B}_{1}+2 \mathrm{~B}_{2}+2 \mathrm{~B}_{3}$ \\
\hline & $A$ & $B_{1}+B_{2}+B_{3}$ & $2 A+B_{1}+B_{2}+B_{3}$ & $A+2 B_{1}+2 B_{2}+2 B_{3}$ & $3 A+2 B_{1}+2 B_{2}+2 B_{3}$ \\
\hline$D_{3}$ & $\mathbf{A}_{1}$ & $A_{2}+E$ & $A_{1}+2 E$ & $\mathrm{~A}_{1}+2 \mathrm{~A}_{2}+2 \mathrm{E}$ & $2 \mathrm{~A}_{1}+\mathrm{A}_{2}+3 \mathrm{E}$ \\
\hline & $A_{i}$ & $A_{2}+E$ & $A_{1}+2 E$ & $A_{t}+2 A_{2}+2 E$ & $2 A_{1}+A_{2}+3 E$ \\
\hline$D_{4}$ & $\mathbf{A}_{1}$ & $A_{2}+E$ & $A_{1}+B_{1}+B_{2}+E$ & $A_{2}+B_{1}+B_{2}+2 E$ & $2 A_{1}+A_{2}+B_{1}+B_{2}+2 E$ \\
\hline & $A_{1}$ & $A_{2}+E$ & $A_{1}+B_{1}+B_{2}+E$ & $A_{2}+B_{1}+B_{2}+2 E$ & $2 A_{1}+A_{2}+B_{1}+B_{2}+2 E$ \\
\hline$D_{5}$ & $\mathbf{A}_{1}$ & $A_{2}+E_{1}$ & $A_{1}+E_{1}+E_{2}$ & $A_{2}+E_{1}+2 E_{2}$ & $\mathrm{~A}_{1}+2 \mathrm{E}_{1}+2 \mathrm{E}_{2}$ \\
\hline & $A_{1}$ & $A_{2}+E_{I}$ & $A_{1}+E_{1}+E_{2}$ & $A_{2}+E_{1}+2 E_{2}$ & $A_{I}+2 E_{I}+2 E_{2}$ \\
\hline$D_{6}$ & $\mathbf{A}_{1}$ & $A_{2}+E_{1}$ & $A_{1}+E_{1}+E_{2}$ & $A_{2}+B_{1}+B_{2}+E_{1}+E_{2}$ & $A_{1}+B_{1}+B_{2}+E_{1}+2 E_{2}$ \\
\hline & $A_{I}$ & $A_{2}+E_{l}$ & $A_{1}+E_{1}+E_{2}$ & $A_{2}+B_{l}+B_{2}+E_{l}+E_{2}$ & $A_{1}+B_{1}+B_{2}+E_{1}+2 E_{2}$ \\
\hline$D_{2 h}$ & $\mathbf{A}_{\mathrm{g}}$ & $B_{1 g}+B_{2 g}+B_{3 g}$ & $2 A_{g}+B_{1 g}+B_{2 g}+B_{3 g}$ & $A_{g}+2 B_{1 g}+2 B_{2 g}+2 B_{3 g}$ & $3 \mathrm{~A}_{\mathrm{g}}+2 \mathrm{~B}_{1 \mathrm{~g}}+2 \mathrm{~B}_{2 \mathrm{~g}}+2 \mathrm{~B}_{3 \mathrm{~g}}$ \\
\hline & $A_{u}$ & $B_{l u}+B_{2 u}+B_{3 u}$ & $2 A_{u}+B_{1 u}+B_{2 u}+B_{3 u}$ & $A_{u}+2 B_{I u}+2 B_{2 u}+2 B_{3 u}$ & $3 A_{u}+2 B_{l u}+2 B_{2 u}+2 B_{3 u}$ \\
\hline$D_{3 h}$ & $\mathbf{A}_{i}^{\prime}$ & $\mathrm{A}_{2}^{\prime}+\mathrm{E}^{\prime \prime}$ & $A_{1}^{\prime}+E^{\prime}+E^{\prime \prime}$ & $A_{1}^{\prime \prime}+A_{2}^{\prime}+A_{2}^{\prime \prime}+E^{\prime}+E^{\prime \prime}$ & $A_{1}^{\prime}+A_{1}^{\prime \prime}+A_{2}^{\prime \prime}+2 E^{\prime}+E^{\prime \prime}$ \\
\hline & $A_{i}^{\prime \prime}$ & $A_{2}^{\prime \prime}+E^{\prime}$ & $A_{i}^{\prime \prime}+E^{\prime}+E^{\prime \prime}$ & $A_{1}^{\prime}+A_{2}^{\prime}+A_{2}^{\prime \prime}+E^{\prime}+E^{\prime \prime}$ & $A_{i}^{\prime}+A_{1}^{\prime \prime}+A_{2}^{\prime}+E^{\prime}+2 E^{\prime \prime}$ \\
\hline$D_{4 h}$ & $A_{1 g}$ & $A_{2 z}+E_{g}$ & $A_{1 g}+B_{1 g}+B_{2 g}+E_{8}$ & $A_{2 g}+B_{1 g}+B_{2 g}+2 E_{g}$ & $2 \mathrm{~A}_{1 \mathrm{~g}}+\mathrm{A}_{2 \mathrm{~g}}+\mathrm{B}_{1 \mathrm{~g}}+\mathrm{B}_{2 \mathrm{~g}}+2 \mathrm{E}_{\mathrm{g}}$ \\
\hline & $A_{\text {Iu }}$ & $A_{2 u}+E_{u}$ & $A_{l u}+B_{l u}+B_{2 u}+E_{u}$ & $A_{2 u}+B_{1 u}+B_{2 u}+2 E_{u}$ & $2 A_{1 u}+A_{2 u}+B_{1 u}+B_{2 u}+2 E_{u}$ \\
\hline$D_{5 h}$ & $\mathbf{A}_{i}$ & $\mathbf{A}_{2}^{\prime}+\mathbf{E}_{1}^{\prime \prime}$ & $A_{1}^{\prime}+E_{1}^{\prime \prime}+E_{2}^{\prime}$ & $A_{2}^{\prime}+E_{1}^{\prime \prime}+E_{2}^{\prime}+E_{2}^{\prime \prime}$ & $A_{1}^{\prime}+E_{1}^{\prime}+E_{1}^{\prime \prime}+E_{2}^{\prime}+E_{2}^{\prime \prime}$ \\
\hline & $\boldsymbol{A}_{i}^{\prime \prime}$ & $A_{2}^{\prime \prime}+E_{l}^{i}$ & $A_{1}^{\prime \prime}+E_{1}^{\prime}+E_{2}^{\prime \prime}$ & $A_{2}^{\prime \prime}+E_{I}^{\prime}+E_{2}^{\prime}+E_{2}^{\prime \prime}$ & $A_{1}^{\prime \prime}+E_{l}^{\prime}+E_{l}^{\prime \prime}+E_{2}^{\prime}+E_{2}^{\prime \prime}$ \\
\hline$D_{6 h}$ & $\mathbf{A}_{1 \mathrm{~g}}$ & $A_{2 g}+E_{1 g}$ & $A_{1 g}+E_{1 g}+E_{2 B}$ & $A_{2 g}+B_{1 g}+B_{2 g}+E_{1 g}+E_{2 g}$ & $\mathrm{~A}_{1 \mathrm{~g}}+\mathrm{B}_{1 \mathrm{~g}}+\mathrm{B}_{2 \mathrm{~g}}+\mathrm{E}_{1 \mathrm{~g}}+2 \mathrm{E}_{2 \mathrm{~g}}$ \\
\hline & $A_{l u}$ & $A_{2 \mu}+E_{2 \mu}$ & $A_{l u}+E_{l u}+E_{2 u}$ & $A_{2 u}+B_{1 u}+B_{2 u}+E_{1 u}+E_{2 u}$ & $A_{l u}+B_{1 u}+B_{2 u}+E_{l u}+2 E_{2 u}$ \\
\hline$D_{2 d}$ & $\mathbf{A}_{1}$ & $A_{2}+E$ & $A_{1}+B_{1}+B_{2}+E$ & $A_{2}+B_{1}+B_{2}+2 E$ & $2 A_{1}+A_{2}+B_{1}+B_{2}+2 E$ \\
\hline & $B_{1}$ & $B_{2}+E$ & $A_{I}+A_{2}+B_{i}+E$ & $A_{1}+A_{2}+B_{2}+2 E$ & $A_{1}+A_{2}+2 B_{1}+B_{2}+2 E$ \\
\hline$D_{3 d}$ & $\mathrm{~A}_{1 \mathrm{~g}}$ & $A_{2 g}+E_{g}$ & $\mathrm{~A}_{1 \mathrm{~g}}+2 \mathrm{E}_{\mathrm{g}}$ & $\mathrm{A}_{1 \mathrm{~g}}+2 \mathrm{~A}_{2 \mathrm{~g}}+2 \mathrm{E}_{\mathrm{g}}$ & $2 \mathrm{~A}_{1 \mathrm{~g}}+\mathrm{A}_{2 \mathrm{~g}}+3 \mathrm{E}_{\mathrm{g}}$ \\
\hline & $A_{l u}$ & $A_{2 u}+E_{u}$ & $A_{l u}+2 E_{\mathrm{u}}$ & $A_{l u}+2 A_{2 u}+2 E_{u}$ & $2 A_{1 u}+A_{2 u}+3 E_{u}$ \\
\hline
\end{tabular}


APPENDIX 1 continued.

\begin{tabular}{|c|c|c|c|c|c|}
\hline $\begin{array}{l}\text { Point } \\
\text { group }\end{array}$ & $\begin{array}{l}\mathrm{D}^{(0+)} \\
D^{(0-)}\end{array}$ & $\begin{array}{l}\mathrm{D}^{(1+)} \\
D^{(1-)}\end{array}$ & $\begin{array}{l}\mathrm{D}^{(2+)} \\
D^{(2-)}\end{array}$ & $\begin{array}{l}D^{(3+)} \\
D^{(3-)}\end{array}$ & $\begin{array}{l}\mathrm{D}^{(4+)} \\
D^{(4-)}\end{array}$ \\
\hline$D_{4 d}$ & $\begin{array}{l}A_{1} \\
B_{1}\end{array}$ & $\begin{array}{l}\mathrm{A}_{2}+\mathrm{E}_{3} \\
B_{2}+E_{2}\end{array}$ & $\begin{array}{l}A_{1}+E_{2}+E_{3} \\
B_{1}+E_{1}+E_{2}\end{array}$ & $\begin{array}{l}A_{2}+E_{1}+E_{2}+E_{3} \\
B_{2}+E_{1}+E_{2}+E_{3}\end{array}$ & $\begin{array}{l}\mathrm{A}_{1}+\mathrm{B}_{1}+\mathrm{B}_{2}+\mathrm{E}_{1}+\mathrm{E}_{2}+\mathrm{E}_{3} \\
A_{1}+A_{2}+B_{1}+E_{1}+E_{2}+E_{3}\end{array}$ \\
\hline$D_{s d}$ & $A_{i g}$ & $\begin{array}{l}\mathrm{A}_{2 \mathrm{~g}}+\mathrm{E}_{1 \mathrm{~g}} \\
A_{2 u}+E_{I u}\end{array}$ & $\begin{array}{l}A_{1 \mathrm{~g}}+E_{1 \mathrm{~g}}+\mathrm{E}_{2 \mathrm{~g}} \\
A_{l u}+E_{l u}+E_{2 u}\end{array}$ & $\begin{array}{l}\mathrm{A}_{2 g}+\mathrm{E}_{18}+2 \mathrm{E}_{2 \mathrm{~g}} \\
A_{2 u}+E_{7 u}+2 E_{2 u}\end{array}$ & $\begin{array}{l}\mathrm{A}_{1 \mathrm{~g}}+2 \mathrm{E}_{1 \mathrm{~g}}+2 \mathrm{E}_{2 \mathrm{~g}} \\
A_{1 u}+2 E_{l u}+2 E_{2 u}\end{array}$ \\
\hline \multirow{2}{*}{$D_{6 d}$} & $A_{1}$ & $A_{2}+E_{5}$ & $A_{1}+E_{2}+E_{5}$ & $A_{2}+E_{2}+E_{3}+E_{5}$ & $A_{1}+E_{2}+E_{3}+E_{4}+E_{5}$ \\
\hline & $B_{1}$ & $B_{2}+E_{1}$ & $B_{1}+E_{1}+E_{4}$ & $B_{2}+E_{1}+E_{3}+E_{4}$ & $B_{1}+E_{1}+E_{2}+E_{3}+E_{4}$ \\
\hline \multirow{2}{*}{$C_{\infty}$} & $\Sigma^{+}$ & $\Sigma^{-}+\Pi$ & $\Sigma^{+}+\Pi+\Delta$ & $\Sigma^{-}+\Pi+\Delta+\Phi$ & $\Sigma^{+}+\Pi+\Delta+\Phi+\Gamma$ \\
\hline & $\Sigma^{-}$ & $\Sigma^{+}+\Pi$ & $\Sigma^{-}+\Pi+\Delta$ & $\Sigma^{+}+\Pi+\Delta+\Phi$ & $\Sigma^{+} \Pi+\Delta+\Phi+\Gamma$ \\
\hline \multirow{2}{*}{$D_{\propto h}$} & $\Sigma_{\mathrm{g}}^{+}$ & $\Sigma_{g}^{-}+\Pi_{g}$ & $\Sigma_{g}^{+}+\Pi_{\mathrm{g}}+\Delta_{\mathrm{g}}$ & $\Sigma_{g}^{-}+\Pi_{g}+\Delta_{g}+\Phi_{B}$ & $\Sigma_{g}^{+}+\Pi_{g}+\Delta_{g}+\Phi_{g}+\Gamma_{g}$ \\
\hline & $\Sigma_{u}^{-}$ & $\Sigma_{u}^{+}+\Pi_{u}$ & $\Sigma_{u}^{-}+\Pi_{u}+\Delta_{u}$ & $\Sigma_{u}^{+}+\Pi_{u}+\Delta_{u}+\Phi_{u}$ & $\Sigma_{u}^{-}+\Pi_{u}+\Delta_{u}+\Phi_{u}+\Gamma_{u}$ \\
\hline \multirow[t]{2}{*}{$T$} & A & $\mathrm{T}$ & $\mathrm{E}+\mathrm{T}$ & $A+2 T$ & $A+E+2 T$ \\
\hline & $A$ & $T$ & $E+T$ & $A+2 T$ & $A+E+2 T$ \\
\hline \multirow[t]{2}{*}{$T_{h}$} & $\mathbf{A}_{\mathrm{g}}$ & $T_{g}$ & $\mathrm{E}_{\mathrm{g}}+\mathrm{T}_{\mathrm{g}}$ & $\mathrm{A}_{\mathrm{g}}+2 \mathrm{~T}_{\mathrm{g}}$ & $A_{g}+E_{g}+2 T_{g}$ \\
\hline & $A_{u}$ & $T_{u}$ & $E_{u}^{6}+T_{u}^{b}$ & $A_{u}+2 T_{u}$ & $A_{u}+E_{u}+2 T_{u}$ \\
\hline \multirow[t]{2}{*}{$T_{d}$} & $\mathbf{A}_{1}$ & $\mathrm{~T}_{1}$ & $\mathrm{E}+\mathrm{T}_{2}$ & $A_{2}+T_{1}+T_{2}$ & $A_{1}+E+T_{1}+T_{2}$ \\
\hline & $A_{2}$ & $T_{2}$ & $E+T_{1}$ & $A_{1}+T_{1}+T_{2}$ & $A_{2}+E+T_{1}+T_{2}$ \\
\hline \multirow[t]{2}{*}{$\mathrm{O}$} & $\mathbf{A}_{1}$ & $T_{1}$ & $\mathrm{E}+\mathrm{T}_{2}$ & $A_{2}+T_{1}+T_{2}$ & $A_{1}+E+T_{1}+T_{2}$ \\
\hline & $A_{1}$ & $T_{1}$ & $E+T_{2}$ & $A_{2}+T_{1}+T_{2}$ & $A_{1}+E+T_{1}+T_{2}$ \\
\hline \multirow[t]{2}{*}{$\mathrm{O}_{h}$} & $A_{1 g}$ & $\mathrm{~T}_{18}$ & $\mathrm{E}_{\mathrm{g}}+\mathrm{T}_{2 \mathrm{~g}}$ & $A_{2 g}+T_{1 g}+T_{2 g}$ & $A_{1 g}+E_{g}+T_{1 g}+T_{2 g}$ \\
\hline & $A_{i u}$ & $T_{I u}$ & $E_{u}+T_{2 u}$ & $A_{2 u}+T_{1 u}+T_{2 u}$ & $A_{l u}+E_{u}+T_{l u}+T_{2 u}$ \\
\hline \multirow[t]{2}{*}{$I$} & A & $\mathrm{T}_{1}$ & $\mathrm{H}$ & $\mathrm{T}_{2}+\mathrm{G}$ & $\mathbf{G}+\mathbf{H}$ \\
\hline & $A$ & $T_{1}$ & $H$ & $T_{2}+G$ & $G+H$ \\
\hline \multirow[t]{2}{*}{$I_{h}$} & $\mathbf{A}_{\mathrm{g}}$ & $\mathbf{T}_{1 \mathrm{~g}}$ & $\mathbf{H}_{\mathrm{g}}$ & $\mathrm{T}_{2 \mathrm{~B}}+\mathrm{G}_{\mathrm{g}}$ & $\mathrm{G}_{\mathrm{g}}+\mathrm{H}_{\mathrm{g}}$ \\
\hline & $A_{u}$ & $T_{1 u}^{6}$ & $H_{u}$ & $T_{2 u}+G_{u}$ & $G_{u}+H_{u}$ \\
\hline
\end{tabular}

APPENDIX 2. Weights allowed under the irreducible representations of the common molecular and crystallographic point groups in response tensors up to rank four

\begin{tabular}{|c|c|c|c|c|c|c|c|c|c|}
\hline \multirow[b]{2}{*}{ Parity } & & \multicolumn{2}{|c|}{ Rank 1} & \multicolumn{2}{|c|}{ Rank 2} & \multicolumn{2}{|c|}{ Rank 3} & \multicolumn{2}{|c|}{ Rank 4} \\
\hline & & + & - & + & - & + & - & + & - \\
\hline$C_{1}$ & $A$ & (1) & (1) & $(012)$ & $(012)$ & $(0123)$ & (0123) & $(01234)$ & (01234) \\
\hline$C_{i}$ & $\begin{array}{l}A_{g} \\
A_{u}\end{array}$ & (1) & (1) & $(012)$ & $(012)$ & $(0123)$ & (0123) & $(01234)$ & (01234) \\
\hline$C_{s}$ & $\begin{array}{l}A^{\prime} \\
A^{\prime \prime}\end{array}$ & $\begin{array}{l}(1) \\
(1)\end{array}$ & $\begin{array}{l}\text { (1) } \\
\text { (1) }\end{array}$ & $\begin{array}{l}(012) \\
(12)\end{array}$ & $\begin{array}{l}(12) \\
(012)\end{array}$ & $\begin{array}{l}(0123) \\
(123)\end{array}$ & $\begin{array}{l}(123) \\
(0123)\end{array}$ & $\begin{array}{l}(01234) \\
(1234)\end{array}$ & $\begin{array}{l}(1234) \\
(01234)\end{array}$ \\
\hline$C_{2}$ & $\begin{array}{l}A \\
B\end{array}$ & $\begin{array}{l}(1) \\
(1)\end{array}$ & $\begin{array}{l}\text { (1) } \\
\text { (1) }\end{array}$ & $\begin{array}{l}(012) \\
(12)\end{array}$ & $\begin{array}{l}(012) \\
(12)\end{array}$ & $\begin{array}{l}(0123) \\
(123)\end{array}$ & $\begin{array}{l}(0123) \\
(123)\end{array}$ & $\begin{array}{l}(01234) \\
(1234)\end{array}$ & $\begin{array}{l}(01234) \\
(1234)\end{array}$ \\
\hline$C_{3}$ & $\begin{array}{l}A \\
E\end{array}$ & (1) & $\begin{array}{l}\text { (1) } \\
\text { (1) }\end{array}$ & $\begin{array}{l}(012) \\
(12)\end{array}$ & $\begin{array}{l}(012) \\
(12)\end{array}$ & $\begin{array}{l}(0123) \\
(123)\end{array}$ & $\begin{array}{l}(0123) \\
(123)\end{array}$ & $\begin{array}{l}(01234) \\
(1234)\end{array}$ & $\begin{array}{l}(01234) \\
(1234)\end{array}$ \\
\hline$C_{4}$ & $\begin{array}{l}A \\
B \\
E\end{array}$ & $\begin{array}{l}\text { (1) } \\
\text { (1) }\end{array}$ & $\begin{array}{l}\text { (1) } \\
\text { (1) }\end{array}$ & $\begin{array}{l}(012) \\
(2) \\
(12)\end{array}$ & $\begin{array}{l}(012) \\
(2) \\
(12)\end{array}$ & $\begin{array}{l}(0123) \\
(23) \\
(123)\end{array}$ & $\begin{array}{l}(0123) \\
(23) \\
(123)\end{array}$ & $\begin{array}{l}(01234) \\
(234) \\
(1234)\end{array}$ & $\begin{array}{l}(01234) \\
(234) \\
(1234)\end{array}$ \\
\hline$C_{5}$ & $\begin{array}{l}A \\
E_{1} \\
E_{2}\end{array}$ & $\begin{array}{l}(1) \\
(1)\end{array}$ & $\begin{array}{l}(1) \\
(1)\end{array}$ & $\begin{array}{l}(012) \\
(12) \\
(2)\end{array}$ & $\begin{array}{l}(012) \\
(12) \\
(2)\end{array}$ & $\begin{array}{l}(0123) \\
(123) \\
(23)\end{array}$ & $\begin{array}{l}(0123) \\
(123) \\
(23)\end{array}$ & $\begin{array}{l}(01234) \\
(1234) \\
(234)\end{array}$ & $\begin{array}{l}(01234) \\
(1234) \\
(234)\end{array}$ \\
\hline$C_{6}$ & $\begin{array}{l}A \\
B \\
E_{1} \\
E_{2}\end{array}$ & (1) & $\begin{array}{l}\text { (1) } \\
(1)\end{array}$ & $\begin{array}{l}(012) \\
(12) \\
(2)\end{array}$ & $\begin{array}{l}(012) \\
(12) \\
(2)\end{array}$ & $\begin{array}{l}(0123) \\
(3) \\
(123) \\
(23)\end{array}$ & $\begin{array}{l}(0123) \\
(3) \\
(123) \\
(23)\end{array}$ & $\begin{array}{l}(01234) \\
(34) \\
(1234) \\
(234)\end{array}$ & $\begin{array}{l}(01234) \\
(34) \\
(1234) \\
(234)\end{array}$ \\
\hline$S_{4}$ & $\begin{array}{l}A \\
B \\
E\end{array}$ & $(1)$ & (1) & $\begin{array}{l}(012) \\
(2)\end{array}$ & $\begin{array}{l}(2) \\
(012)\end{array}$ & $\begin{array}{l}(0123) \\
(23)\end{array}$ & $\begin{array}{l}(23) \\
(0123)\end{array}$ & $\begin{array}{l}(01234) \\
(234)\end{array}$ & $\begin{array}{l}(234) \\
(01234) \\
(1234)\end{array}$ \\
\hline$S_{6}$ & $\begin{array}{l}E \\
A_{\mathrm{g}} \\
E_{\mathrm{g}}\end{array}$ & $\begin{array}{l}(1) \\
(1) \\
(1)\end{array}$ & (1) & $\begin{array}{l}(12) \\
(012) \\
(12)\end{array}$ & (12) & $\begin{array}{l}(123) \\
(0123) \\
(123)\end{array}$ & $(123)$ & $\begin{array}{l}(1234) \\
(01234) \\
(1234)\end{array}$ & 34) \\
\hline & $\begin{array}{l}A_{\mathrm{u}} \\
E_{\mathrm{u}}\end{array}$ & & $\begin{array}{l}(1) \\
(1)\end{array}$ & & $\begin{array}{l}(012) \\
(12)\end{array}$ & & $\begin{array}{l}(0123) \\
(123)\end{array}$ & & $\begin{array}{l}(01234) \\
(1234)\end{array}$ \\
\hline$S_{\mathrm{k}}$ & $\begin{array}{l}A \\
B \\
E_{1} \\
E_{2} \\
E_{3}\end{array}$ & (1) & (1) & $\begin{array}{l}(2) \\
(12)\end{array}$ & $\begin{array}{l}(012) \\
(12) \\
(2)\end{array}$ & $\begin{array}{l}(0123) \\
(3) \\
(23) \\
(123)\end{array}$ & $\begin{array}{l}(0123) \\
(123) \\
(23) \\
(3)\end{array}$ & $\begin{array}{l}(01234) \\
(4) \\
(34) \\
(234) \\
(1234)\end{array}$ & $\begin{array}{l}(4) \\
(01234) \\
(1234) \\
(234) \\
(34)\end{array}$ \\
\hline
\end{tabular}


Appendix 2. continued.

\begin{tabular}{|c|c|c|c|c|c|c|c|c|c|}
\hline \multirow{2}{*}{ Parity } & & \multicolumn{2}{|c|}{ Rank 1} & \multicolumn{2}{|c|}{ Rank 2} & \multicolumn{2}{|c|}{ Rank 3} & \multicolumn{2}{|c|}{ Rank 4} \\
\hline & & + & - & + & - & + & - & + & - \\
\hline \multirow[t]{6}{*}{$s_{10}$} & $A_{g}$ & (1) & & $(012)$ & & $(0123)$ & & $(01234)$ & \\
\hline & $E_{\mathrm{lg}}$ & (1) & & (12) & & (123) & & (1234) & \\
\hline & $E_{2 g}$ & & & (2) & & (23) & & $(234)$ & \\
\hline & $A_{u}$ & & (1) & & $(012)$ & & $(0123)$ & & (01234) \\
\hline & $E_{l u}$ & & (1) & & (12) & & (123) & & (1234) \\
\hline & $E_{2 u}$ & & & & (2) & & $(23)$ & & (234) \\
\hline \multirow[t]{4}{*}{$C_{2 h}$} & $A_{\mathrm{g}}$ & (1) & & $(012)$ & & $(0123)$ & & $(01234)$ & \\
\hline & $B_{q}$ & (1) & & (12) & & (123) & & (1234) & \\
\hline & $A_{\mathrm{u}}$ & & (1) & & $(012)$ & & $(0123)$ & & $(01234)$ \\
\hline & $\boldsymbol{B}_{\mathrm{u}}$ & & (1) & & (12) & & $(123)$ & & $(1234)$ \\
\hline \multirow[t]{4}{*}{$C_{3 h}$} & $A^{\prime}$ & (1) & & $(012)$ & & $(0123)$ & (3) & $(01234)$ & (34) \\
\hline & $E^{\prime}$ & & (1) & (2) & (12) & (23) & $(123)$ & $(234)$ & (1234) \\
\hline & $A^{\prime \prime}$ & & (1) & & $(012)$ & (3) & $(0123)$ & (34) & (01234) \\
\hline & $E^{\prime \prime}$ & (1) & & (12) & (2) & (123) & (23) & (1234) & (234) \\
\hline \multirow[t]{6}{*}{$C_{4 h}$} & $A_{g}$ & (1) & & $(012)$ & & (0123) & & $(01234)$ & \\
\hline & $B_{g}$ & & & (2) & & (23) & & (234) & \\
\hline & $E_{g}$ & (1) & & (12) & & (123) & & (1234) & \\
\hline & $A_{t u}$ & & (1) & & $(012)$ & & $(0123)$ & & (01234) \\
\hline & $B_{u}$ & & & & (2) & & (23) & & (234) \\
\hline & $E_{u}$ & & (1) & & (12) & & (123) & & (1234) \\
\hline \multirow[t]{6}{*}{$C_{5 h}$} & $A^{\prime}$ & (1) & & $(012)$ & & (0123) & & (01234) & \\
\hline & $E_{i}^{\prime}$ & & (1) & & (12) & & $(123)$ & (4) & $(1234)$ \\
\hline & $E_{2}^{\prime}$ & & & (2) & & (23) & (3) & (234) & (34) \\
\hline & $A^{\prime \prime}$ & & (1) & & $(012)$ & & (0123) & & (01234) \\
\hline & $E_{1}^{\prime \prime}$ & (1) & & (12) & & (123) & & (1234) & (4) \\
\hline & $E_{2}^{\prime \prime}$ & & & & (2) & (3) & (23) & (34) & (234) \\
\hline \multirow[t]{8}{*}{$C_{6 h}$} & $A_{g}$ & (1) & & $(012)$ & & (0123) & & $(01234)$ & \\
\hline & $B_{g}$ & & & & & (3) & & $(34)$ & \\
\hline & $E_{\mathrm{lg}}$ & (1) & & (12) & & (123) & & (1234) & \\
\hline & $E_{2 g}^{\prime}$ & & & $(2)$ & & (23) & & (234) & \\
\hline & $A_{u}$ & & (1) & & $(012)$ & & $(0123)$ & & (01234) \\
\hline & $B_{u}$ & & & & & & (3) & & $(34)$ \\
\hline & $E_{1 u}$ & & (1) & & (12) & & (123) & & (1234) \\
\hline & $E_{2 u}$ & & & & (2) & & (23) & & (234) \\
\hline \multirow[t]{4}{*}{$C_{2 t}$} & $A_{1}$ & & (1) & $(02)$ & (12) & $(023)$ & (123) & (0234) & (1234) \\
\hline & $A_{2}$ & (1) & & (12) & (02) & (123) & $(023)$ & (1234) & (0234) \\
\hline & $B_{1}$ & (1) & (1) & (12) & (12) & (123) & $(123)$ & (1234) & $(1234)$ \\
\hline & $B_{2}$ & (1) & (1) & (12) & (12) & (123) & (123) & (1234) & (1234) \\
\hline$C_{3 n}$ & $A_{1}$ & & (1) & $(02)$ & (1) & $(023)$ & (13) & $(0234)$ & (134) \\
\hline & $A_{2}$ & (1) & & (1) & $(02)$ & (13) & $(023)$ & (134) & $(0234)$ \\
\hline & $E$ & (1) & (1) & (12) & (12) & (123) & (123) & (1234) & (1234) \\
\hline$C_{40}$ & $A_{1}$ & & (1) & $(02)$ & (1) & $(02)$ & (13) & $(024)$ & (134) \\
\hline & $A_{2}$ & (1) & & (1) & $(02)$ & (13) & $(02)$ & (134) & $(024)$ \\
\hline & $B_{1}$ & & & (2) & (2) & (23) & (23) & $(234)$ & (234) \\
\hline & $B_{2}$ & & & (2) & (2) & (23) & (23) & (234) & (234) \\
\hline & $E$ & (1) & (1) & (12) & (12) & (123) & $(123)$ & (1234) & (1234) \\
\hline$C_{5_{r}}$ & $A_{1}$ & & (1) & $(02)$ & (1) & $(02)$ & (13) & $(024)$ & (13) \\
\hline & $A_{2}$ & (1) & & (1) & $(02)$ & (13) & $(02)$ & (13) & $(024)$ \\
\hline & $E_{1}$ & (1) & (1) & (12) & (12) & (123) & (123) & (1234) & (1234) \\
\hline & $E_{2}$ & & & (2) & (2) & (23) & (23) & $(234)$ & $(234)$ \\
\hline$C_{t \prime \prime}$ & $A_{1}$ & & (1) & $(02)$ & (1) & $(02)$ & (13) & $(024)$ & (13) \\
\hline & $A_{2}$ & (1) & & (1) & $(02)$ & (13) & $(02)$ & (13) & $(024)$ \\
\hline & $B_{1}$ & & & & & (3) & (3) & (34) & (34) \\
\hline & $B_{2}$ & & & & & (3) & (3) & (34) & (34) \\
\hline & $E_{1}$ & (1) & (1) & (12) & (12) & (123) & (123) & (1234) & (1234) \\
\hline & $E_{2}$ & & & (2) & (2) & (23) & (23) & $(234)$ & (234) \\
\hline$D_{2}$ & $A$ & & & $(02)$ & $(02)$ & $(023)$ & $(023)$ & $(0234)$ & $(0234)$ \\
\hline & $B_{1}$ & (1) & (1) & (12) & (12) & $(123)$ & (123) & (1234) & $(1234)$ \\
\hline & $B_{2}$ & (1) & (1) & (12) & (12) & $(123)$ & (123) & (1234) & (1234) \\
\hline & $B_{3}$ & (1) & (1) & (12) & (12) & (123) & (123) & (1234) & (1234) \\
\hline$D_{3}$ & $A_{1}$ & & & $(02)$ & $(02)$ & $(023)$ & $(023)$ & $(0234)$ & $(0234)$ \\
\hline & $A_{2}$ & (1) & (1) & (1) & (1) & (13) & (13) & (134) & (134) \\
\hline & $E$ & (1) & (1) & (12) & (12) & (123) & (123) & (1234) & (1234) \\
\hline
\end{tabular}


APPENDIX 2. continued.

\begin{tabular}{|c|c|c|c|c|c|c|c|c|c|}
\hline \multirow{2}{*}{ Parity } & & \multicolumn{2}{|c|}{ Rank 1} & \multicolumn{2}{|c|}{ Rank 2} & \multicolumn{2}{|c|}{ Rank 3} & \multicolumn{2}{|c|}{ Rank 4} \\
\hline & & + & - & + & - & + & - & + & - \\
\hline \multirow[t]{5}{*}{$D_{4}$} & $A_{1}$ & & & $(02)$ & $(02)$ & (02) & $(02)$ & (024) & $(024)$ \\
\hline & $A_{2}$ & (1) & (1) & (1) & (1) & (13) & (13) & (134) & (134) \\
\hline & $B_{1}$ & & & (2) & (2) & (23) & (23) & (234) & (234) \\
\hline & $B_{2}$ & & & (2) & (2) & (23) & (23) & (234) & (234) \\
\hline & $E$ & (1) & (1) & (12) & (12) & (123) & (123) & (1234) & (1234) \\
\hline \multirow{4}{*}{$D_{5}$} & $A_{3}$ & & & $(02)$ & $(02)$ & (02) & (02) & (024) & $(024)$ \\
\hline & $A_{2}$ & (1) & $(1)$ & (1) & (1) & (13) & (13) & (13) & (13) \\
\hline & $E_{1}$ & (1) & (1) & (12) & (12) & (123) & (123) & (1234) & (1234) \\
\hline & $E_{2}$ & & & (2) & (2) & (23) & (23) & (234) & (234) \\
\hline \multirow[t]{6}{*}{$D_{6}$} & $A_{1}$ & & & (02) & $(02)$ & $(02)$ & $(02)$ & (024) & $(024)$ \\
\hline & $A_{2}$ & (1) & (1) & (1) & (1) & (13) & (13) & (13) & (13) \\
\hline & $B_{1}$ & & & & & (3) & (3) & (34) & (34) \\
\hline & $B_{2}$ & & & & & (3) & (3) & (34) & (34) \\
\hline & $E_{1}$ & (1) & $(1)$ & $(12)$ & $(12)$ & (123) & (123) & (1234) & (1234) \\
\hline & $E_{2}$ & & & (2) & (2) & (23) & $(23)$ & (234) & (234) \\
\hline \multirow[t]{8}{*}{$D_{2 h}$} & $A_{g}$ & & & (02) & & $(023)$ & & (0234) & \\
\hline & $B_{1 g}$ & (1) & & (12) & & (123) & & (1234) & \\
\hline & $B_{2 g}$ & (1) & & (12) & & (123) & & (1234) & \\
\hline & $B_{3 g}$ & (1) & & (12) & & (123) & & (1234) & \\
\hline & $A_{u}$ & & & & $(02)$ & & $(023)$ & & (0234) \\
\hline & $B_{1 \mu}$ & & (1) & & (12) & & (123) & & (1234) \\
\hline & $B_{2 u}$ & & (1) & & (12) & & (123) & & (1234) \\
\hline & $B_{3 u}$ & & (1) & & (12) & & (123) & & (1234) \\
\hline \multirow[t]{6}{*}{$D_{3 h}$} & $A_{1}^{\prime}$ & & & (02) & & $(02)$ & (3) & $(024)$ & (34) \\
\hline & $A_{2}^{\prime}$ & (1) & & (1) & & (13) & (3) & (13) & (34) \\
\hline & $E^{\prime}$ & & (1) & (2) & (12) & (23) & (123) & (234) & (1234) \\
\hline & $A_{1}^{\prime \prime}$ & & & & (02) & (3) & $(02)$ & (34) & $(024)$ \\
\hline & $A_{2}^{\prime \prime}$ & & (1) & & (1) & (3) & (13) & (34) & (13) \\
\hline & $E^{\prime \prime}$ & (1) & & (12) & (2) & (123) & (23) & (1234) & (234) \\
\hline \multirow[t]{10}{*}{$D_{4 h}$} & $A_{1 g}$ & & & (02) & & $(02)$ & & $(024)$ & \\
\hline & $A_{2 g}$ & (1) & & (1) & & (13) & & (134) & \\
\hline & $B_{\lg }$ & & & (2) & & (23) & & (234) & \\
\hline & $B_{2 g}$ & & & (2) & & (23) & & (234) & \\
\hline & $E_{g}$ & (1) & & (12) & & (123) & & (1234) & \\
\hline & $A_{1 u}$ & & & & (02) & & $(02)$ & & $(024)$ \\
\hline & $A_{2 u}$ & & (1) & & (1) & & (13) & & (134) \\
\hline & $B_{1 u}$ & & & & (2) & & (23) & & (234) \\
\hline & $B_{2 u}$ & & & & (2) & & (23) & & (234) \\
\hline & $E_{u}$ & & $(1)$ & & (12) & & (123) & & (1234) \\
\hline \multirow{8}{*}{$D_{5 h}$} & $A_{i}^{\prime}$ & & & $(02)$ & & $(02)$ & & $(024)$ & \\
\hline & $A_{2}^{\prime}$ & (1) & & (1) & & (13) & & (13) & \\
\hline & $E_{1}^{\prime}$ & & (1) & & (12) & & $(123)$ & (4) & (1234) \\
\hline & $E_{2}^{\prime}$ & & & (2) & & (23) & (3) & (234) & (34) \\
\hline & $A_{1}^{\prime \prime}$ & & & & $(02)$ & & (02) & & (024) \\
\hline & $A_{2}^{\prime \prime}$ & & & & (1) & & (13) & & (13) \\
\hline & $E_{1}^{\prime \prime}$ & (1) & & $(12)$ & & (123) & & (1234) & (4) \\
\hline & $E_{2}^{\prime \prime}$ & & & & (2) & (3) & (23) & (34) & $(234)$ \\
\hline$D_{\text {fii }}$ & $A_{\mathrm{lg}}$ & & & $(02)$ & & $(02)$ & & $(024)$ & \\
\hline & $A_{2 g}$ & (1) & & (1) & & (13) & & (13) & \\
\hline & $B_{1 g}$ & & & & & (3) & & (34) & \\
\hline & $B_{2 g}$ & & & & & (3) & & (34) & \\
\hline & $E_{1 g}$ & (1) & & (12) & & (123) & & (1234) & \\
\hline & $E_{2 k}$ & & & $(2)$ & & (23) & & (234) & \\
\hline & $A_{1 u}$ & & & & $(02)$ & & $(02)$ & & $(024)$ \\
\hline & $\mathbf{A}_{2 u}$ & & (1) & & (1) & & (13) & & (13) \\
\hline & $B_{1,}$ & & & & & & (3) & & (34) \\
\hline & $B_{2 u}$ & & & & & & (3) & & (34) \\
\hline & $E_{\mathrm{lu}}$ & & (1) & & (12) & & (123) & & (1234) \\
\hline & $E_{2 n}$ & & & & (2) & & (23) & & (234) \\
\hline$D_{2 d}$ & $A_{1}$ & & & $(02)$ & (2) & $(02)$ & (23) & $(024)$ & (234) \\
\hline & $A_{2}$ & (1) & & (1) & (2) & (13) & (23) & (134) & (234) \\
\hline & $B_{1}$ & & & (2) & (02) & (23) & (02) & (234) & $(024)$ \\
\hline
\end{tabular}


APPENDIX 2. continued

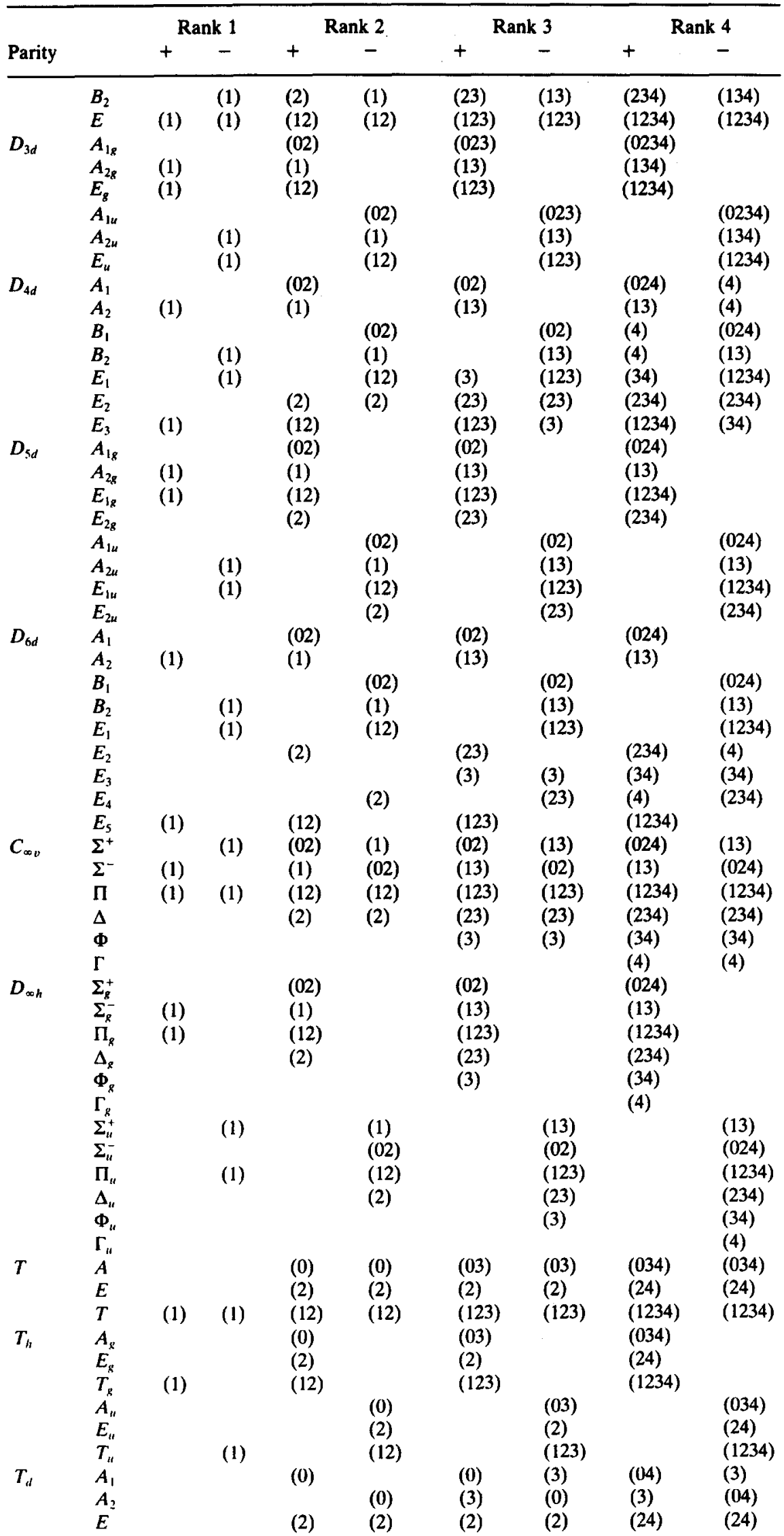


APPENDIX 2. continued.

\begin{tabular}{|c|c|c|c|c|c|c|c|c|c|}
\hline \multirow{2}{*}{ Parity } & & \multicolumn{2}{|c|}{ Rank 1} & \multicolumn{2}{|c|}{ Rank 2} & \multicolumn{2}{|c|}{ Rank 3} & \multicolumn{2}{|c|}{ Rank 4} \\
\hline & & + & - & + & - & + & - & + & - \\
\hline \multirow{7}{*}{$O$} & $T_{1}$ & (1) & & (1) & (2) & (13) & (23) & $(134)$ & (234) \\
\hline & $T_{2}$ & & (1) & (2) & (1) & (23) & (13) & (234) & (134) \\
\hline & $A_{1}$ & & & (0) & (0) & (0) & (0) & (04) & (04) \\
\hline & $A_{2}$ & & & & & (3) & (3) & (3) & (3) \\
\hline & $E$ & & & (2) & (2) & (2) & (2) & (24) & (24) \\
\hline & $T_{1}$ & (1) & (1) & (1) & (1) & (13) & (13) & (134) & (134) \\
\hline & $T_{2}$ & & & (2) & (2) & (23) & (23) & (234) & (234) \\
\hline \multirow[t]{10}{*}{$o_{k}$} & $A_{18}$ & & & (0) & & (0) & & (04) & \\
\hline & $A_{28}$ & & & & & (3) & & (3) & \\
\hline & $E_{g}$ & & & (2) & & (2) & & (24) & \\
\hline & $T_{18}^{b}$ & (1) & & (1) & & (13) & & (134) & \\
\hline & $T_{2 g}^{\circ}$ & & & (2) & & (23) & & (234) & \\
\hline & $A_{1 u}$ & & & & (0) & & $(0)$ & & $(04)$ \\
\hline & $A_{2 u}$ & & & & & & (3) & & (3) \\
\hline & $E_{u}$ & & & & (2) & & (2) & & (24) \\
\hline & $T_{1 u}$ & & (1) & & (1) & & (13) & & (134) \\
\hline & $T_{2 u}$ & & & & (2) & & (23) & & (234) \\
\hline \multirow[t]{5}{*}{$I$} & $A$ & & & (0) & (0) & $(0)$ & (0) & (0) & (0) \\
\hline & $T_{1}$ & (1) & (1) & (1) & (1) & (1) & (1) & (1) & (1) \\
\hline & $T_{2}$ & & & & & (3) & (3) & (3) & (3) \\
\hline & $G$ & & & & & (3) & (3) & (34) & (34) \\
\hline & $H$ & & & (2) & (2) & (2) & (2) & (24) & (24) \\
\hline \multirow[t]{10}{*}{$I_{h}$} & $A_{g}$ & & & (0) & & $(0)$ & & (0) & \\
\hline & $T_{1 \mathrm{~g}}$ & (1) & & (1) & & (1) & & (1) & \\
\hline & $T_{28}^{8}$ & & & & & (3) & & (3) & \\
\hline & $G_{g}$ & & & & & (3) & & (34) & \\
\hline & $H_{g}^{g}$ & & & (2) & & (2) & & (24) & \\
\hline & $A_{u}^{8}$ & & & & (0) & & $(0)$ & & $(0)$ \\
\hline & $T_{1 u}$ & & (1) & & (1) & & (1) & & (1) \\
\hline & $T_{2 u}$ & & & & & & (3) & & (3) \\
\hline & $G_{u}$ & & & & & & (3) & & (34) \\
\hline & $H_{u}$ & & & & (2) & & (2) & & (24) \\
\hline
\end{tabular}

